\section{Relationship among Periodontal Disease, Insulin Resistance, Salivary Cortisol, and Stress Levels during Pregnancy}

Ana Paula Castilho Garcia Seraphim ${ }^{1}$, Fernando Yamamoto Chiba ${ }^{1}$, Renato Felipe Pereira ${ }^{2}$, Maria Sara de Lima Coutinho Mattera², Suzely Adas Saliba Moimaz', Doris Hissako Sumida²

\author{
'Department of Child and Social \\ Dentistry, Araçatuba Dental School, \\ UNESP - Universidade Estadual \\ Paulista, Araçatuba, SP, Brazil \\ ${ }^{2}$ Department of Basic Sciences, \\ Araçatuba Dental School, \\ UNESP - Universidade Estadual \\ Paulista, Araçatuba, SP, Brazil
}

Correspondence: Doris Hissako Sumida, Rua José Bonifácio, 1193, Vila Mendonça, 16015-050 Araçatuba, SP, Brasil. Tel: \pm 55-018-3636-2819. e-mail: dorishs@foa.unesp.br

\begin{abstract}
Pregnancy is a period involving important metabolic changes that enable the maintenance of the mother's health and development of the fetus. This study aimed to assess the relationship among periodontal disease, insulin resistance, salivary cortisol concentration and level of perceived stress in pregnant women. This was a cross-sectional study. The sample comprised 96 pregnant women between the fifth and seventh month of pregnancy registered at the Basic Health Units of the Unified Health System (SUS). The periodontal condition was assessed after obtainment free and informed consent from the participants. Participants were divided into three groups: control subjects with a healthy periodontal condition ( $\mathrm{CN} ; \mathrm{n}=46)$, patients with gingivitis $(\mathrm{Gl} ; \mathrm{n}=26)$, and patients with periodontitis ( $\mathrm{Pl} ; \mathrm{n}=24)$. Saliva and blood samples were collected for evaluation of salivary cortisol concentration, glycemia, insulinemia and Homeostasis Model Assessment-Insulin Resistance index. A validated survey for the assessment of perceived stress levels was also performed. PI group showed significantly higher $(\mathrm{p}<0.05)$ blood glucose levels $(\mathrm{CN}$ :

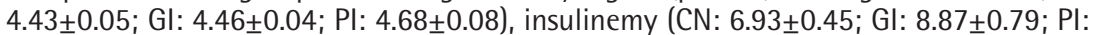
$12.77 \pm 1.30)$, insulin resistance ( $\mathrm{CN}: 1.40 \pm 0.10$; GI: $1.81 \pm 0.18$; PI: $2.66 \pm 0.29)$ compared with the $\mathrm{CN}$ and $\mathrm{GI}$ groups. The levels of perceived stress were higher $(\mathrm{p}<0.05)$ in $\mathrm{PI}$ and GI groups when compared to CN group (CN: 20.5 \pm 1.26 ; GI: $25.8 \pm 1.95$; PI: $26.6 \pm 1.36$ ). There was no significant difference in the concentration of salivary cortisol between the groups (CN: $11.13 \pm 0.58 ; \mathrm{Gl}: 11.96 \pm 0.74 ; \mathrm{PI}: 11.47 \pm 0.74)$. It was concluded that there is a relationship between higher levels of perceived stress, insulin resistance and the occurrence of periodontal disease during pregnancy. This study emphasizes the importance of preventing periodontitis in order to avoid insulin resistance and stress during pregnancy since these can cause systemic complications for the mother and the fetus.
\end{abstract}

Key Words: pregnancy, gestational diabetes, periodontal diseases, hydrocortisone, physiological stress.

\section{Introduction}

Gestational diabetes mellitus (GDM) can be defined as an intolerance to glucose of any degree that begins during pregnancy. It usually develops in the second trimester of pregnancy and disappears after birth (1). GDM affects approximately $16.9 \%$ of pregnant women between the ages of 20 and 49 years. In 2013, approximately 21.4 million newborns were affected by GDM, with over $90 \%$ of cases occurring in low and middle income countries (2).

Pregnancy is a period involving important metabolic and hormonal changes that enable the maintenance of the mother's health and adequate development of the fetus (3). The increased levels of estrogens, such as progesterone, can cause changes in the immune response, gingival capillary dilatation, and the release of gingival exudate, potentially explaining the exacerbation of gingival inflammation during pregnancy (4).

Gingivitis (GI) affects approximately $60 \%$ to $75 \%$ of pregnant women and is characterized as an inflammatory disease of the soft tissues surrounding the tooth. In contrast, periodontitis (PI) affects a smaller proportion of pregnant women ( 30\%); however, it has more severe consequences, namely the destruction of tooth support structures that may result in tooth loss (5). Studies have shown that stress conditions can significantly alter the immunological and behavioral response of the individual. Furthermore, an increased susceptibility to periodontal disease is known to be caused by an imbalance between the host response and the action of pathogenic microorganisms. Therefore, it is important to consider stress as a predisposing factor for the development of periodontal disease (6).

Stress can be quantified through the perceived stress scale (PSS) (7). High levels of perceived stress, measured by PSS, may be associated with physiological imbalances such as high levels of cortisol (8). Elevations in cortisol can be enhanced by emotional factors typical of the changes that occur during pregnancy (9). Furthermore, cortisol can stimulate hepatic gluconeogenesis and inhibit glucose 
uptake induced by insulin in skeletal muscle and adipose tissue, consequently contributing to the development of insulin resistance (10).

Therefore, this study aimed to assess the relationship between periodontal disease, insulin resistance, salivary cortisol concentration and the level of perceived stress in pregnant women (5 to 7 months of pregnancy), and to investigate a potential correlation with the onset of GDM.

\section{Material and Methods}

This was a qualitative and quantitative cross-sectional study. The sample comprised 96 pregnant women from a Brazilian municipality registered at Basic Health Units of the Unified Health System (SUS) within a five-month period.

The pregnant women invited to participate in the study met the following inclusion criteria: 20 to 40 years old and between the fifth and seventh month of pregnancy. Exclusion criteria included: obesity, diabetes, alcoholism, drug abuse, history of macrosomic newborns, advanced periodontal disease with spontaneous bleeding interfering with salivary collection, depressive disorders, victims of domestic violence and smoking.

All participants provided written consent and the study was approved as a minimal risk study by the Research Ethics Committee (protocol no. 81845), according to the criteria of the Resolution 466 of the National Health Council on research involving human subjects.

\section{Periodontal Examination}

Periodontal tissue health was assessed using the Community Periodontal Index (CPI). A single examiner collected the data in a dental chair using a reflector, a mirror and a periodontal probe. The mouth was divided into sextants and six sites of each tooth index (teeth \#17, 16, 11, $26,27,47,46,31,36$ and 37 ) were evaluated. The highest code was recorded according to the following criteria: 0 (healthy), 1 (gingival bleeding after probing), 2 (presence of supra- or subgingival calculus), 3 (4-5 $\mathrm{mm}$ periodontal pocket), and 4 (periodontal pocket of at least $6 \mathrm{~mm}$ ). The pocket depth was determined with a periodontal probe, using the distance from the base of the periodontal pocket to the free gingival margin. The participants of the study were classified as either: control with healthy periodontal condition - $\mathrm{CN}(\mathrm{CPI}=0)$, with gingivitis - $\mathrm{GI}(\mathrm{CPI}=1$ or 2$)$ or with periodontitis - $\mathrm{PI}(\mathrm{CPI}=3$ or 4$)$.

\section{Blood Pressure}

Blood pressure was measured on the same occasion using a mercury aneroid sphygmomanometer with the cuff placed on the left arm of the pregnant mother in the sitting position, after 5 min of rest. A blood pressure $\geq 140 / 90 \mathrm{mmHg}$ was considered as hypertension.

\section{Salivary Cortisol}

Salivary collection was performed between 7:30 a.m. and 8:00 a.m., directly into a Salivette tube (Salivette ${ }^{\circledR}$; Genese Produtos Diagnósticos Ltda, São Paulo, SP, Brazil). The participants were informed not to eat or brush their teeth in the $2 \mathrm{~h}$ preceding collection. The tubes were properly capped and stored at $-20^{\circ} \mathrm{C}$ to keep the samples stable. The Salivettes were centrifuged at $1000 \times \mathrm{g}$ for 2 min, resulting in a clean and fluid saliva sample that was used to determine the cortisol salivary concentration. Salivary cortisol was measured by competitive enzyme linked immunosorbent assay (ELISA) method, by using a commercial kit (Diametra DK0020, Milano, Italy). According to the manufacturer, the lowest detectable concentration of cortisol that can be distinguished from the calibrator 0 is $0.12 \mathrm{ng} / \mathrm{mL}$ at the $95 \%$ confidence limit.

\section{Glycemy, Insulinemy and Homeostasis Model} Assessment-Insulin Resistance Evaluation

To determine the blood glucose and insulin concentrations, venous blood samples $(5 \mathrm{~mL})$ were collected between 7:30 a.m. and 8:00 a.m. by venipuncture via median cubital vein after the women had fasted overnight for 8 to 12 hours. Tubes used in the blood collection for analysis of glycemia had sodium fluoride as a glycolytic inhibitor and EDTA as anticoagulant (BD Vacutainer ${ }^{\text {TM }}$ Fluoride/EDTA; Becton, Dickinson (t Co., NJ, USA); and tubes for analysis of insulinemia had sodium heparin as anticoagulant (BD Vacutainer $^{\mathrm{TM}}$ Plus; Becton, Dickinson). The blood samples were centrifuged immediately after collection at 1800 $\mathrm{g}$ for $15 \mathrm{~min}$ at $4{ }^{\circ} \mathrm{C}$ to obtain plasma. Samples from the plasma were used for the determination of glycemy using the oxidase glucose method (enzymatic glucose; ANALISA Diagnóstica, Belo Horizonte, MG, Brazil) and for insulinemy using the radioimmunology method (Coat-ACount; DPC, Diagnostic Products, Los Angeles, CA, USA). Insulin resistance was evaluated by the Homeostasis Model Assessment Insulin Resistance (HOMA-IR) index calculated by the formula: HOMA - IR = fasting glycemia $(\mathrm{mmol} / \mathrm{L}) \mathrm{x}$ fasting insulinemia $(\mu \mathrm{UI} / \mathrm{mL}) / 22.5$.

\section{Stress Evaluation}

Stress levels were evaluated by the Perceived Stress Scale (PSS) translated and validated for Portuguese. The 10-question version was used since it produced similar results to the 14-question PSS version. Regarding the scale results, it is common practice to classify the scores in categories, such as low, medium, and high. However, the PSS authors do not recommend this approach, since adding scores of the same category reduces the statistical precision (7). Since PSS scores are continuous, they should not be grouped or added as this approach prevents analysis of the individual factors 
(7). The PSS was carefully applied, following the guidelines of the authors (7), namely, the requirement of beginning each question with, "in the past month, how often did you...". It was confirmed that the participants understood that the questions they answered referred to how they felt over the past month and the scale's options for answers (never, rarely, sometimes, often, and always) were repeated at the end of every question. In addition, the participants had access to the printed survey in order to read the questions and answers. Finally, after each answer, the question and the answer were read to the interviewee.

\section{Statistical Analysis}

Statistical analysis was performed with the program Graph Pad Prism (version 5.0) using analysis of variance followed by Tukey's test. All values are presented as the mean \pm standard error of the mean (SEM) and differences between groups were considered significant when $p<0.05$.

\section{Results}

A total of 96 racially diverse (CN: $54.35 \%$ Caucasian, $41.30 \%$ brown and $4.35 \%$ black; GI: $53.85 \%$ white, $42.31 \%$ brown and 3.85\% black; PI: 56.52\% Caucasian, 39.13\% brown and $4.35 \%$ black;) pregnant women were eligible to participate of the study after application of the exclusion criteria and obtainment of the written consent. Of this total, according to results of the periodontal examination, the participants were divided in control subjects with a healthy periodontal condition $(n=46)$, patients with gingivitis $(n=26)$, and patients with periodontitis $(n=24)$. The average age of the patients was 26.18 years. All pregnant women were resident in low-income urban areas of the city.

\section{Glycemy, Insulinemy, Homeostasis Model Assessment- Insulin Resistance and Salivary Cortisol}

The values of glycemy, insulinemy, HOMA-IR and salivary cortisol concentration are shown in Table 1. The PI group showed significantly higher values for all parameters

Table 1. Glycemia, insulinemia, Homeostasis Model Assessment-Insulin Resistance index (HOMA-IR) and cortisol salivary concentration in pregnant women with a healthy periodontal condition (CN), gingivitis (GI) or periodontitis (PI)

\begin{tabular}{lccc}
\hline Parameter & CN & GI & PI \\
\hline Glucose $(\mathrm{mmol} / \mathrm{L})$ & $4.43 \pm 0.05$ & $4.46 \pm 0.04$ & $4.68 \pm 0.08^{* \#}$ \\
Insulin $(\mu \mathrm{U} / \mathrm{mL})$ & $6.93 \pm 0.45$ & $8.87 \pm 0.79$ & $12.77 \pm 1.30^{* \#}$ \\
HOMA-IR & $1.40 \pm 0.10$ & $1.81 \pm 0.18$ & $2.66 \pm 0.29^{* \#}$ \\
Cortisol $(\mathrm{ng} / \mathrm{mL})$ & $11.13 \pm 0.58$ & $11.96 \pm 0.74$ & $11.47 \pm 0.74$ \\
\hline
\end{tabular}

Values presented as mean \pm standard error of the mean. ${ }^{*} \mathrm{p}<0.05$ compared with the CN. \#p<0.05 compared with the GI. compared with the $\mathrm{CN}$ and $\mathrm{Gl}$ groups, except for the concentration of salivary cortisol, for which no difference was observed between the groups.

\section{Evaluation of Perceived Stress Levels}

The $\mathrm{Pl}$ and $\mathrm{Gl}$ groups showed higher levels of perceived stress compared with the $\mathrm{CN}$ group (Fig. 1).

\section{Discussion}

In this study, an association between periodontitis, insulin resistance and the level of perceived stress in women between the fifth and seventh month of pregnancy, was observed.

Several studies have shown that there is a bidirectional relationship between periodontal disease and GDM. Therefore, GDM can be considered a major risk factor for the development of periodontitis. Periodontitis, in turn, has been considered a predisposing factor to GDM (11). Although the relationship between GDM and periodontitis is well established, further studies evaluating different populations are needed to improve the knowledge about this relationship (12). Shirakashi et al. (13) have shown that maternal periodontal disease in rats may promote fetal programming. An increase in the degree of phosphorylation of IRS-1 serine in adipose tissue (that causes a decrease in insulin signal), as well as increased plasma concentrations of tumor necrosis factor alpha (TNF- $\alpha$ ), interleukin 6 and resistin were observed in the adult offspring of rats with periodontal disease (13). Furthermore, periodontal pathogens can reach the amniotic cavity and cause adverse pregnancy outcomes, including preterm birth and/or low birth weight (14).

The findings of the present study showed a higher insulin resistance (identified by the HOMA-IR index) in the PI group

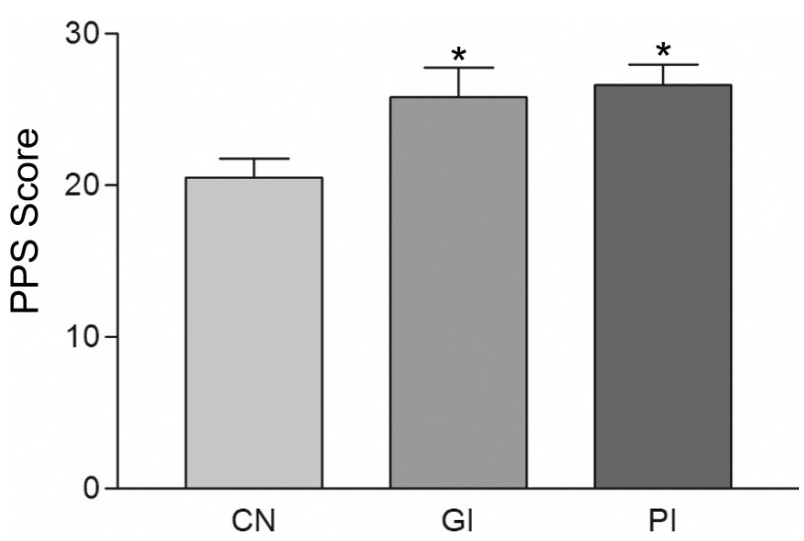

Figure 1. Perceived stress level (PPS) scores in control pregnant women with healthy periodontal condition (CN), gingivitis (GI) or periodontitis (PI). Values as presented as mean \pm standard error. ${ }^{*} \mathrm{p}<0.05$ compared with the CN. 
compared with the other groups. This is in agreement with a previous study (15), showing that women with GDM had a higher prevalence of periodontitis compared with those without GDM. Although the mechanisms involved in these changes are not fully understood, periodontitis infection is known to induce an immune response from the host, where the bacteria and their products stimulate the local production of pro-inflammatory cytokines by infiltrating leukocytes in inflamed periodontal tissues (16). These locally produced cytokines, such as TNF- $\alpha$, may eventually reach the systemic circulation and act on distant tissues of the oral cavity, perturbing the insulin signal and causing insulin resistance (11). Another study (17) showed that chronic periodontitis is associated with plasma levels of TNF- $\alpha$ in patients with type 2 diabetes, supporting the hypothesis that periodontal infection may contribute to inflammation and insulin resistance. TNF- $\alpha$ can damage the insulin signal transduction by reducing IRS-1 phosphorylation on tyrosine residues (18). It can also cause damage by stimulating serine kinases, such as I B kinase and c-Jun amino terminal kinase that promote IRS-1 phosphorylation on serine residues, resulting in the attenuation of the insulin signal (19). Studies in vitro

\section{patients (21).}

It is known that black women showed higher insulin resistance compared to other ethnic groups (22), however, in this study the distribution of black women in those 3 groups was homogeneous, showing that ethnicity didn't interfere in the results related to insulin resistance.

Periodontitis can be influenced by several local and systemic factors, including psychological stress. Some studies have shown that besides negatively influencing the treatment of periodontitis, psychological stress may be a risk factor for the development and exacerbation of periodontitis (23). Although there was no significant difference recorded in the salivary cortisol levels between the different groups, the present study showed that pregnant women in the PI group had higher perceived stress levels, according to the PSS. It has been suggested that psychosocial stress may influence the oral hygiene and this may alter the extent and severity of periodontitis (24). Ishisaka et al. (25) evaluated serum cortisol concentrations, psychological stress states and periodontal clinical parameters. The results demonstrated a significant correlation between serum cortisol levels and the severity of periodontitis, supporting the view that stress can be a factor contributing to the development of periodontitis.

In another study (26), an increase in maternal salivary cortisol levels at 14 weeks of gestation was not observed. However, a difference was observed in the $30^{\text {th }}$ week. These data partially corroborate our results, since in the present study a single analysis between the fifth and seventh month of pregnancy was performed. Since the participants were patients of the public health system, additional dosages could not be administered, constituting a limitation of the present study. It should also be noted that this study is one of the first to investigate the relationship among periodontitis, insulin resistance, salivary cortisol concentration and level of perceived stress in pregnant women between the fifth and seventh month of pregnancy.

We conclude that there is a relationship between higher levels of perceived stress, insulin resistance and the occurrence of periodontitis during pregnancy. Therefore, this study emphasizes the importance of preventing periodontitis in order to avoid insulin resistance and stress during pregnancy, since these can cause systemic complications for the mother and the fetus.

\section{Resumo}

A gravidez é um periodo que envolve alterações metabólicas importantes que permitem a manutenção da saúde e desenvolvimento fetal e materno. Este estudo teve como objetivo avaliar a relação entre doença periodontal, resistência à insulina, concentração de cortisol salivar e nível de estresse percebido em gestantes. Trata-se de um estudo transversal. A amostra foi composta por 96 gestantes entre o quinto e sétimo mês, registradas em Unidades Básicas de Saúde do Sistema Único de Saúde. A condição periodontal foi avaliada após a obtenção do consentimento livre e esclarecido das participantes. As participantes foram divididas em três grupos: pacientes controle com condição periodontal saudável $(\mathrm{CN} ; \mathrm{n}=46)$, com gengivite ( $\mathrm{Gl} ; \mathrm{n}=26)$ e com periodontite $(\mathrm{Pl} ; \mathrm{n}=24)$. As amostras salivares e sanguineas foram coletadas para avaliação da concentração salivar de cortisol, glicemia, insulinemia e índice HOMAIR. Foi aplicado um questionário validado para verificação dos niveis de estresse percebido. Grupo Pl apresentou niveis significativamente mais elevados $(p<0,05)$ de glicose no sangue ( $C N: 4,43 \pm 0,05 ; \mathrm{GI}: 4,46 \pm 0,04$; PI: $4,68 \pm 0,08)$, insulinemia (CN: 6,93 $\pm 0,45 ; \mathrm{Gl}: 8,87 \pm 0,79 ; \mathrm{PI}: 12,77 \pm 1,30$ ), resistência à insulina ( $\mathrm{CN}: 1,40 \pm 0,10 ; \mathrm{GI}: 1,81 \pm 0,18$; PI: $2,66 \pm 0,29)$ em comparação com os grupos $\mathrm{CN}$ e Gl. Os níveis de estresse percebido foram maiores $(\mathrm{p}<0,05)$ nos grupos $\mathrm{Pl}$ e $\mathrm{Gl}$ quando comparados ao grupo


significativa na concentração de cortisol salivar entre os grupos (CN: $11,13 \pm 0,58$; GI: $11,96 \pm 0,74$; PI: $11,47 \pm 0,74)$. Concluiu-se que há uma relação entre os niveis mais elevados de estresse percebido, resistência à insulina e ocorrência da doença periodontal durante a gravidez. Este estudo enfatiza a importância de prevenir a periodontite, a fim de evitar a resistência à insulina e estresse durante a gravidez, uma vez que estes podem causar complicações sistêmicas para a mãe e para o feto.

\section{References}

1. Hayes $\mathrm{C}$. Long-term prognostic factors in the diagnosis of gestational diabetes. Br J Nurs 2009;18:523-526.

2. Guariguata L, Linnenkamp U, Beagley J, Whiting DR, Cho NH. Global estimates of the prevalence of hyperglycaemia in pregnancy. Diabetes Res Clin Pract 2014;103:176-185.

3. Kirwan JP, Hauguel-De Mouzon S, Lepercq J, Challier JC, Huston-Presley 
$\mathrm{L}$, Friedman JE, et al.. TNF-alpha is a predictor of insulin resistance in human pregnancy. Diabetes 2002;51:2207-2213.

4. Yalcin $F$, Eskinazi $E$, Soydine $M$, Basegmez $C$, Issever $H$. The effect of sociocultural status on periodontal condictions in pregnancy. J Periodontol 2002;73:178-182.

5. Silk $H$, Douglass AB, Douglass JM, Silk L. Oral health during pregnancy. Am Fam Physician 2008;77:1139-1144.

6. Ayub LG, Novaes J, Belém A, Grisi MFM, Souza LSL, Palioto DB, et al.. Stress as possible risk factor for periodontal disease - literature review. R. Periodontia 2010;20:28-36.

7. Cohen S, Karmack T, Mermelstein R. A global measure of perceived stress. J Health Soc Behav 1983;24:385-396.

8. Goldman N, Glei DA, Seplaki C, Liu IW, Weinstein M. Perceived stress and physiological dysregulation in older adults. Stress 2005;8:95-105.

9. Buss C, Davis EP, Shahbaba B, Pruessner JC, Head K, Sandman CA. Maternal cortisol over the course of pregnancy and subsequent child amygdala and hippocampus volumes and affective problems. PNAS [serial online] 2012 April [cited 2015 Sep 22]; [8 screens]. Available from: URL: http://www.pnas.org/content/109/20/E1312.full.pdf

10. Freemark M. Regulation of maternal metabolism by pituitary and placental hormones: roles in fetal development and metabolic programming. Horm Res 2006;65:41-49.

11. Colombo NH, Shirakashi DJ, Chiba FY, Coutinho SL, Ervolino E, Garbin $\mathrm{CA}$, et al.. Periodontal disease decreases insulin sensitivity and insulin signaling. J Periodontol 2012;83:864-870.

12. Ruiz DR, Romito GA, Dib SA. Periodontal disease in gestational and type I diabetes mellitus pregnant women. Oral Dis 2011;17:515-521.

13. Shirakashi DJ, Leal RP, Colombo NH, Chiba FY, Garbin CA, Jardim EG Jr, et al.. Maternal periodontal disease in rats decreases insulin sensitivity and insulin signaling in adult offspring. J. Periodontol 2013;84;407414.

14. Ercan E, Eratalay K, Deren O, Gur D, Ozyuncu O, Altun B, et al.. Evaluation of periodontal pathogens in amniotic fluid and the role of periodontal disease in pre-term birth and low birth weight. Acta Odontol Scand 2013;71:553-559.

15. Xiong $X$, Elkind-Hirsch $K E$, Xie $Y$, Delarosa R, Maney P, Pridjian G, et al.. Periodontal disease as a potential risk factor for the development of diabetes in women with a prior history of gestational diabetes mellitus. J Public Health Dent 2013;73:41-49.

16. Amar $\mathrm{S}$, Han X. The impact of periodontal infection on systemic diseases. Med Sci Monit 2003;9:291-299.
17. Engebretson S, Chertog R, Nichols A, Hey-Hadavi J, Celenti R, Grbic J. Plasma levels of tumour necrosis factor-alpha in patients with chronic periodontitis and type 2 diabetes. J Clin Periodontol 2007;34:18-24.

18. Hotamisligil GS, Peraldi $P$, Budavari A, Ellis R, White MF, Spiegelman BM. IRS-1 mediated inhibition of insulin receptor tyrosine kinase activity in TNF- alpha- and obesity- induced insulin resistance. Science 1996;271:665-668.

19. Osborn O, Olefsky JM. The cellular and signaling networks linking the immune system and metabolism in disease. Nat Med 2012;18:363-374.

20. Coughlan MT, Oliva K, Georgiou HM, Permezel JM, Rice GE. Glucoseinduced release of tumour necrosis factor-alpha from human placental and adipose tissues in gestational diabetes mellitus. Diabet Med 2001;18:921-927.

21. Munenaga Y, Hiroshima Study Group, Yamashina T, Tanaka J, Nishimura F. Improvement of glycated hemoglobin in Japanese subjects with type 2 diabetes by resolution of periodontal inflammation using adjunct topical antibiotics: Results from the Hiroshima Study. Diabetes Res Clin Pract 2013;100:53-60.

22. Chow CC, Periwal V, Csako G, Ricks M, Courville AB, Miller BV 3rd, et al.. Higher acute insulin response to glucose may determine greater free fatty acid clearance in African-American women. J Clin Endocrinol Metab 2011:96:2456-2463.

23. Bakri I, Douglas CW, Rawlinson A. The effects of stress on periodontal treatment: a longitudinal investigation using clinical and biological markers. J Clin Periodontal 2013;40:955-961.

24. Deinzer $R$, Hilpert $D$, Bach $K$, Schawacht $M$, Herforth A. Effects of academic stress on oral hygiene - a potential link between stress and plaque-associated disease? J Clin Periodontol 2001;28:459-464.

25. Ishisaka A, Ansai T, Soh I, Inenaga K, Awano S, Yoshida A, et al.. Association of cortisol and dehydroepiandrosterone sulphate levels in serum with periodontal status in older Japanese adults. J Clin Periodontol 2008;35:853-861.

26. Obel $C$, Hedegaard M, Henriksen TB, Secher NJ, Olsen J, Levine S. Stress and salivary cortisol during pregnancy. Psychoneuroendocrinology 2005;30:647-656.

Received November 2, 2015 Accepted March 11, 2016 